\title{
Torque Enhancement of Dual Three-Phase PMSM by Harmonic Injection
}

\author{
Yashan $\mathrm{Hu}^{1}$, Keyuan Huang ${ }^{1 *}$, Xuefei $\mathrm{Li}^{1}$, Derong $\mathrm{Luo}^{1}$, Shoudao Huang ${ }^{1}$, and Xiandong $\mathrm{Ma}^{2}$ \\ ${ }^{1}$ College of Electrical and Information Engineering, Hunan University, Changsha, Hunan, China \\ ${ }^{2}$ Department of Engineering, Lancaster University, Lancaster, UK \\ *kyhuang@163.com
}

\begin{abstract}
The torque enhancement of dual three-phase permanent magnet synchronous machine (DT-PMSM) drive system by full exploitation of flux-linkage and current harmonics are comparatively studied in this paper. The torque capability of DT-PMSM is previously evaluated with strategies of harmonics utilization, i.e. Strategy-1 of 3rd harmonic utilization and Strategy-2 of 5th and 7th harmonic utilization, which can extend the torque capability by $18.2 \%$ and $9.0 \%$ respectively. However, the full exploitation of harmonics including 3rd, 5th and 7th harmonics in the dual three-phase system are not addressed. In this paper, the Strategy-3 of 3rd, 5th and 7th harmonic utilization is also included. Its corresponding harmonic current control is proposed and the average torque and harmonic torque are analyzed in detail. Based on a test rig with existing prototype DT-PMSM, the torque with Strategy-3 is increased up to $26.5 \%$, which is superior to the previous strategies.
\end{abstract}

\section{Introduction}

High torque capability is essential for the electric machine drive system in the application of emerging industries such as modern transportation, electrical car, ship propulsion, and wind power generation. The multi-phase drive system presents a trending solution to obtain high power ratings $[1,2]$ due to its multiple power/torque capability of a conventional single three-phase machine within the same current limit of power switch [3].

Except for the configuration of the multi-phase system, there are also some other strategies to further enhance the power/torque capability. The first strategy is to increase the machine's flux density. A typical application is the optimal magnet shaping with 3rd harmonic flux within the flux limit in brushless AC machines [4-6]. The second strategy is the harmonic current injection to the stator currents, e.g. the 3rd harmonic currents or 5th and 7th harmonic current injection to doubly salient synchronous reluctance machines [7] and 2nd harmonic current injection to variable flux reluctance machine [8] to improve the torque performance.

The advantage of the multi-phase system is the additional freedom of harmonic current injection compared to its single three-phase counter-parts [9], which has meant it is possible to enhance the torque by low-order harmonic current injection to stator currents $[10,11]$. There are various applications of harmonic currents utilization in multi-phase machines to improve torque capability; for example, the 3rd harmonic currents are injected into a 5-phase induction machine (IM) torque $[12,13]$ and 5-phase permanent magnet (PM) machine [14] to increase their total average. It is based on the interaction of the 3rd spatial and electrical harmonics, which generate additional torque rotating at the fundamental frequency [12]. Also as detailed in [15], the torque density was enhanced without increasing stator yoke thickness of a dual-rotor, radial-flux 5-phase PM machine with 3rd harmonic current injection. The improved flux pattern of near rectangular shape from no load to full load is achieved by $3 \mathrm{rd}$ harmonic current injection for eleven-phase IMs [16] to avoid flux saturation, reduce iron loss and improve power density. The 3rd, 5th and 7th harmonic currents are injected into stator currents of 9-phase synchronous reluctance machine (SRM) to boost its torque [17]. To increase the torque capability of an eleven-phase IMs, the odd-order harmonics below eleven are injected into the stator currents [18].

Regarding the dual three-phase machine with phase shift (electrical angle) $30^{\circ}$, the torque density is improved significantly in dual three-phase IM [19] and PMSM with 3rd harmonic current injection $[20,21]$. The 5 th and 7 th harmonic currents are also helpful in further enhancement of torque capacity in dual three-phase PMSM (DT-PMSM) drive [22, 23]. It is worth noting that, to inject the 3rd harmonic currents in the DT-PMSM, an extra flowing path is required for the zero-sequence currents; meanwhile, a proper harmonic current regulation is required and the harmonic voltage might increase.

Based on the conventional dual three-phase voltage source inverter (VSI) [24], a modified dual three-phase VSI with 3rd harmonic current injection is shown in Fig. 1, where two single three-phase VSIs are in parallel with the common DC bus. Each set of three-phase windings is driven by a single three-phase VSI, of which the first set of single threephase windings is phase $\mathrm{ABC}$, whilst the other set of single three-phase windings is phase $\mathrm{XYZ}$, which is shifted from phase $\mathrm{ABC}$ by electrical angle $30^{\circ}$. The neutral points of the three-phase windings $\mathrm{ABC}$ and $\mathrm{XYZ}$, as shown in Fig. 1, are connected to the midpoint of two independent DC powers [19].

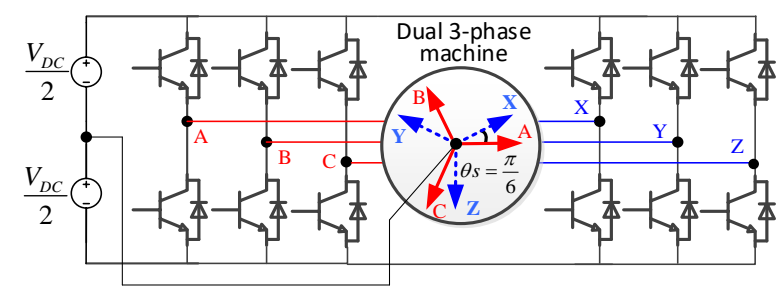

Fig. 1 Dual three-phase drive system with harmonic current injection

In this paper, the full exploitation of harmonics to boost torque capability in the DT-PMSM drive system is investigated systematically, which is an extension study of $[22,23]$. Three different strategies of harmonic injection of flux or current are compared, which include Strategy-1 of 3rd harmonic injection, Strategy-2 of 5 th and 7 th harmonic 
injection and the proposed Strategy-3 of 3rd, 5th and 7th harmonic injection. Compared to the 3rd, 5th and 7th harmonic current injection in 9-phase SRM to improve the torque [17], the proposed method utilizes the 3rd, 5th and 7th harmonics in both current and PM flux in the DT-PMSM.

This paper is organized as follows: firstly, the gains of 3rd, 5th and 7th harmonics in different strategies are optimized in Section 2; meanwhile, the average torque and torque ripple due to harmonics are analyzed in details. Then the torque capability of an existing prototype DT-PMSM by different strategies of harmonic current injection is evaluated in Section 3. The current control scheme of DT-PMSM with harmonic current injection is introduced in Section 4. Extensive experimentation on an existing prototype DTPMSM is conducted to validate the effectiveness of torque enhancement by different strategies in Section 5. The comparative experimental results show that the proposed Strategy-3 has superiority over Strategy-1 and -2 in terms of torque capacity.

\section{Harmonics Optimization and Torque Analysis}

To increase the torque capability, an effective way is the magnet shaping with harmonic flux within the flux limit in the PM machine [4-6]. In this paper, it is assumed that the $3 \mathrm{rd}$, 5th and 7th harmonic flux are dominant harmonics in the DT-PMSM.

\subsection{Coefficients of harmonic injection}

Assuming the phase current or flux-linkage with fundamental, 3rd, 5th and 7th harmonics is expressed as

$$
y\left(\theta_{x}\right)=k_{1}\left(\begin{array}{l}
\cos \left(\theta_{x}\right)+k_{3} \cos \left(3 \theta_{x}+\theta_{3}\right) \\
+k_{5} \cos \left(5 \theta_{x}+\theta_{5}\right)+k_{7} \cos \left(7 \theta_{x}+\theta_{7}\right)
\end{array}\right)
$$

where $k_{1}$ and $\theta_{x}$ is the gain and phase angle of fundamental respectively; $k_{3}, k_{5}$ and $k_{7}$ are relative gains of $3 \mathrm{rd}, 5$ th and 7 th harmonics versus fundamental component respectively; $\theta_{3}, \theta_{5}$ and $\theta_{7}$ are offset angles of $3 \mathrm{rd}$, 5th and 7th harmonics respectively. As the torque mainly depends on the fundamental current and flux-linkage, to maximize fundamental within the same peak value $1 p u$ due to the limit of current or flux density, the gains $k_{3}, k_{5}$ and $k_{7}$ should be optimized. By genetic algorithm, whose optimization procedure is detailed in [25] or by MATLAB Optimization Toolbox (optimtool in MATLAB Command Windows), the gains of optimization with different strategies are listed in Table 1. These strategies are designated as: Strategy-1: 3rd harmonic injection; Strategy-2: 5th and 7th harmonic injection; Strategy-3: 3rd, 5th, and 7th harmonic injection; Strategy-4: 3rd, and 5th harmonic injection; Strategy-5: 3rd, and 7 th harmonic injection.

Table 1 Coefficients of optimization results

\begin{tabular}{llllll}
\hline Gains & $\begin{array}{c}\text { Strategy } \\
1\end{array}$ & $\begin{array}{c}\text { Strategy } \\
2\end{array}$ & $\begin{array}{c}\text { Strategy } \\
3\end{array}$ & $\begin{array}{c}\text { Strategy } \\
4\end{array}$ & $\begin{array}{c}\text { Strategy } \\
5\end{array}$ \\
\hline$k_{3}$ & $-1 / 6$ & 0 & -0.2652 & -0.2321 & -0.164 \\
$\theta_{3}$ & 0 & 0 & 0 & 0 & 0 \\
$k_{5}$ & 0 & -0.1253 & 0.1000 & 0.061 & 0 \\
$\theta_{5}$ & 0 & 0 & 0 & 0 & 0 \\
$k_{7}$ & 0 & 0.0535 & -0.0291 & 0 & 0.018 \\
$\theta_{7}$ & 0 & 0 & 0 & 0 & 0 \\
$k_{1}$ & 1.155 & 1.0774 & 1.2311 & 1.2071 & 1.1708 \\
\hline
\end{tabular}

According to the vector space decomposition (VSD) control for the dual three-phase machine [26, 27], the 3rd, 5th and 7 th harmonics can be categorized into two groups. The 5 th and 7 th harmonics are mapped to harmonic sub-plane, i.e. $z_{1} z_{2}$ sub-plane. The 3rd harmonics are mapped to zerosequence sub-plane, i.e. $o_{1} O_{2}$ sub-plane. Strategy-1 utilizes harmonics in the $\mathrm{O}_{1} \mathrm{O}_{2}$ sub-plane. Strategy-2 utilizes harmonics in the $z_{1} z_{2}$ sub-plane. Strategy-3, 4, and 5 utilize harmonics in both $\mathrm{O}_{1} \mathrm{O}_{2}$ sub-plane and $z_{1} z_{2}$ sub-plane, and Strategy-4 and Strategy-5 are special scenarios of Strategy-3. As the coefficients of fundamental $k_{l}$ in Strategy-4 and Strategy-5 in Table 1 is much less than Strategy-3, consequently, their torque analysis and corresponding experiments will not be introduced for simplicity.

The optimized current or flux-linkage profiles are shown in Fig. 2. It shows that optimized profiles are within $1 p u$, where the base value is the maximum peak current or flux-linkage. The fundamental gains are 1.15pu, 1.077pu and $1.231 \mathrm{pu}$ for Strategy-1, Strategy-2, and Strategy-3 respectively, see [Table 1]. It indicates the fundamental current and flux-linkage can be further increased within the limit by harmonics utilization.

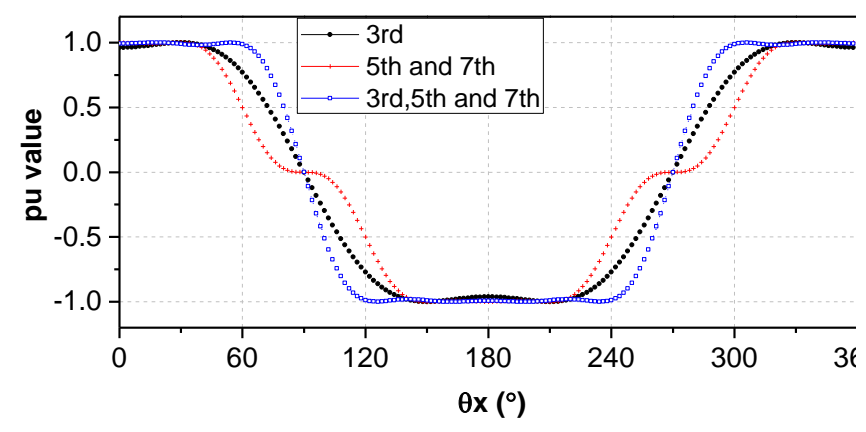

Fig. 2 Current or flux-linkage profiles with harmonics utilization after optimization

\subsection{Torque analysis}

If only the fundamental, 3rd, 5th and 7th harmonic currents are considered, the current of phase A can be expressed as

$$
\begin{aligned}
& i_{a}(\theta)=k_{i 1} \sqrt{2} I_{N} . \\
& \left(\begin{array}{l}
\cos (\theta+\pi / 2)+k_{i 3} \cos \left(3(\theta+\pi / 2)+\theta_{i 3}\right) \\
+k_{i 5} \cos \left(5(\theta+\pi / 2)+\theta_{i 5}\right)+k_{i 7} \cos \left(7(\theta+\pi / 2)+\theta_{i 7}\right)
\end{array}\right)
\end{aligned}
$$

where $\theta$ is PM rotor position, $I_{N}$ is the RMS amplitude of rated current, $\theta_{i 3}, \theta_{i 5}$, and $\theta_{i 7}$ are offset angles of $3 \mathrm{rd}$, 5th and 7 th harmonic currents, $k_{i l}$ is the gain of fundamental, $k_{i 3}, k_{i 5}$ and $k_{i 7}$ are relative gains of $3 \mathrm{rd}$, 5 th and 7 th harmonic currents to fundamental current.

If only the fundamental, 3rd, 5th and 7th harmonic flux-linkages are considered, similar to the expression of the current (2) the back-EMF of phase A can be expressed as

$$
\begin{aligned}
& e_{a}(\theta)=k_{e 1} \sqrt{2} E_{N} . \\
& \left(\begin{array}{l}
\cos (\theta+\pi / 2)+ \\
3 k_{e 3} \cos \left(3(\theta+\pi / 2)+\theta_{e 3}\right)+ \\
5 k_{e 5} \cos \left(5(\theta+\pi / 2)+\theta_{e 5}\right)+7 k_{e 7} \cos \left(7(\theta+\pi / 2)+\theta_{e 7}\right)
\end{array}\right)
\end{aligned}
$$


where $E_{N}$ is the RMS amplitude of rated back-EMF, $\theta_{e 3}, \theta_{e 5}$ and $\theta_{e} 7$ are the offset angles of 3rd, 5th and 7th back harmonic EMFs, $k_{e l}$ is the gain of fundamental, $3 k_{e 3}, 5 k_{e 5}$ and $7 k_{e 7}$ are relative gains of $3 \mathrm{rd}$, 5th and 7 th back harmonic EMFs to fundamental back-EMF. It is worth noting that the EMF is the differential of flux-linkage; therefore, the coefficients of $n$th harmonic EMF are $n$ times of coefficients of $n$th harmonic flux-linkage.

The phase currents and back-EMFs of phase B, C, X, $\mathrm{Y}$ and $\mathrm{Z}$ have similar expression as (2) and (3) respectively, which can be expressed as

$$
\begin{aligned}
& F_{x}(\theta)=F_{a}\left(\theta-\theta_{s}\right) \\
& F_{b}(\theta)=F_{a}\left(\theta-4 \theta_{s}\right) \\
& F_{y}(\theta)=F_{a}\left(\theta-5 \theta_{s}\right) \\
& F_{c}(\theta)=F_{a}\left(\theta-8 \theta_{s}\right) \\
& F_{z}(\theta)=F_{a}\left(\theta-9 \theta_{s}\right)
\end{aligned}
$$

where $\theta_{s}$ is the phase shift angle between phase ABC and $\mathrm{XYZ}$, which is $\pi / 6$ in this case study; " $F$ " represents phase current " $i$ " or back-EMF " $e$ ". If the power related to reluctance torque is neglected, the power related to PM torque can be expressed by (9), which is the accumulation of power from each phase.

$$
P(\theta)=\sum_{p h s=a, b, c, x, y, z} e_{p h s}(\theta) i_{p h s}(\theta)
$$

Therefore, the electromagnetic torque $T_{e}$ can be obtained by the power divided by mechanical speed, i.e.

$$
\begin{aligned}
& T_{e}=P(\theta) / \Omega=6 k_{e 1} k_{i 1} E_{N} I_{N} / \Omega . \\
& \left(\begin{array}{l}
1+ \\
3 k_{e 3} k_{i 3} \cos \left(\theta_{e 3}-\theta_{i 3}\right)+ \\
5 k_{e 5} k_{i 5} \cos \left(\theta_{e 5}-\theta_{i 5}\right)+7 k_{e 7} k_{i 7} \cos \left(\theta_{e 7}-\theta_{i 7}\right)+ \\
5 k_{e 5} k_{i 7} \cos \left(12 \theta+\theta_{e 5}+\theta_{i 7}\right)+7 k_{e 7} k_{i 5} \cos \left(12 \theta+\theta_{e 7}+\theta_{i 5}\right)
\end{array}\right)
\end{aligned}
$$

where $\Omega$ is the machine's mechanical speed. The torque consists of four parts: the first line in the bracket (10) is the torque from the interaction between the fundamental components from flux-linkage and current. The second line in the bracket (10) is the torque from the interaction between the 3rd harmonic flux-linkage and 3rd harmonic currents. The remained parts in bracket (10) are the torque from the interaction between 5 th, 7 th harmonics of current and fluxlinkage.

If the flux and current are optimized according to coefficients shown in Table 1 , then (10) can be simplified as

$$
T_{\mathrm{e}}=\frac{6 E_{N} I_{N}}{\Omega_{\text {rate }}} k_{e 1} k_{i 1}\left(\begin{array}{l}
1+3 k_{e 3} k_{i 3}+5 k_{e 5} k_{i 5}+7 k_{e 7} k_{i 7} \\
+\left(5 k_{e 5} k_{i 7}+7 k_{e 7} k_{i 5}\right) \cos (12 \theta)
\end{array}\right)
$$

The RMS current can be expressed as

$$
I_{r m s}=I_{N} k_{i 1} \sqrt{1+k_{i 3}^{2}+k_{i 5}^{2}+k_{i 7}^{2}}
$$

Therefore, the average torque per RMS current can be expressed as

$$
\frac{T_{\mathrm{e}}}{I_{r m s}} \propto \frac{1+3 k_{e 3} k_{i 3}+5 k_{e 5} k_{i 5}+7 k_{e 7} k_{i 7}}{\sqrt{1+k_{i 3}^{2}+k_{i 5}^{2}+k_{i 7}^{2}}}
$$

Assuming the torque, copper loss, and torque per RMS current without 3rd, 5th and 7th harmonics in flux and stator currents are $1 p u$ when the peak flux and current are $1 p u$, then the torque, copper loss, torque per peak current, and torque per RMS current can be summarized in Table 7 in Appendix with different strategies of harmonics utilization. It is worth noting that $3 \mathrm{rd}$, 5th and 7th harmonics in flux and stator currents are optimized with coefficients listed in Table 1.

The torque per RMS current with different strategies are also listed in Table 7. It shows that the torque per RMS current can increase significantly by harmonic fluxes and can be further enhanced by the combination of harmonic fluxes and currents. The torque per peak current can increase a lot by harmonic current injection. It could be employed in the applications where more torque is required for a short time, for instance, it can be applied in bulldozer, excavator or to improve the starting performance of electric vehicles [23].

For a given DT-PMSM with different strategies of flux optimization, the average torque and the torque per RMS current vary with different strategies of harmonic current injection. As shown in Table 7 in Appendix, the torque capacity can be improved by the different combinations of harmonics utilization. The combination of Strategy-3 for flux optimization and Strategy-1 for current optimization could be an attractive proposal to extend the torque capability up to $1.611 p u$ without torque ripple, which has relatively high torque, high torque per RMS current, and 12th torque ripplefree. If the Strategy-3 is applied to both flux and current, the torque can be improved up to $1.928 p u$ with the cost of $5.8 \%$ 12th harmonic torque ripple and, meanwhile, it has the highest torque per RMS current.

\section{Prototype Dual Three-phase PMSM (DT-PMSM)}

The torque capability extension is discussed based on the optimized current and flux harmonic injection in Section 2. However, for limited conditions, there is no DT-PMSM with optimized flux-linkage shown in Fig. 2 in the lab; therefore, the torque enhancement by harmonic flux could not be fully exposited by experiments. In this paper, an existing prototype DT-PMSM is employed to evaluate the torque capability enhancement by harmonic current injection indeed.

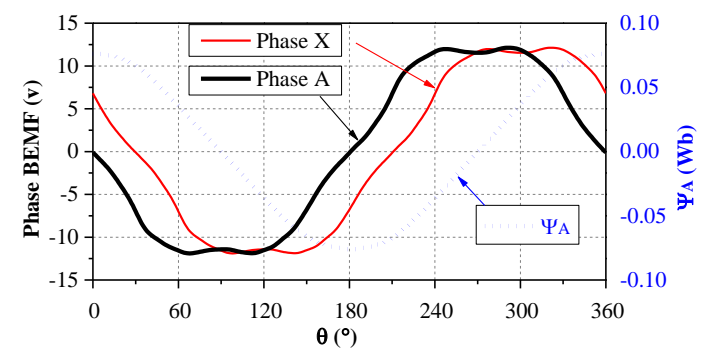

(a)

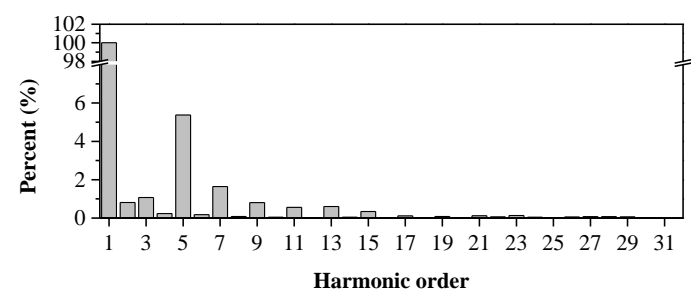

(b)

Fig. 3 Back-EMFs and FFT analysis

(a) Phase A and X back-EMFs and flux $\psi_{A}$, (b) FFT analysis of phase A back-EMF

The measured back-EMFs of the prototype DTPMSM and the flux-linkage of phase A as a function of the rotor position are illustrated in Fig. 3(a). The reconstructed flux-linkage is the integral of measured back-EMF of phase 
A. The harmonics of back-EMF of phase A are shown in Fig. 3(b) and it can be seen that there are abundant 3rd, 5th and 7 th harmonics, while other harmonics are negligible.

By fast Fourier transform (FFT), the measured backEMF of phase A can be expressed as the function of $\theta$ (14)

$$
e_{a}=A_{0}+\sum_{n=1}^{\infty} A_{n} \cos \left(n\left(\theta+\frac{\pi}{2}\right)+\theta_{e n}\right)
$$

where " $A_{n}$ " and " $\theta_{e n}$ " represent the amplitude and offset angle of $n$th harmonics respectively, $A_{0}$ is the DC value, which can be obtained by FFT. The coefficients in Table 1 can be listed in Table 2, where the base value for the amplitude $A_{n}(\mathrm{pu})$ is $A_{l}(\mathrm{~V})$. Ideally, DC value $A_{0}$ is zero, as can be seen from Table 2 , the $A_{0}$ is trivial and can be neglected.

As there are no even order harmonics in the threephase system theoretically and the 3rd, 5th and 7th harmonics are dominant, according to coefficients in Table 2. The fundamental back-EMF will be 1.088 times of back-EMF peak value. Therefore, if the back-EMF is expressed as (3) with peak value $1 p u$, the corresponding coefficients of fundamental and harmonics can be listed in Table 3. The torque of the prototype machine with Strategy-1, Strategy-2 and the proposed Strategy-3 ([Table 1]) can be estimated according to (10) and listed in Table 4. It shows that the Strategy-3 has the highest average torque, which is superior to Strategy-1 and -2 .

Table 2 FFT analysis of phase back-EMF

\begin{tabular}{cccc}
\hline Harmonic order $(\mathrm{n})$ & $A_{n}(\mathrm{~V})$ & $A_{n}(\mathrm{pu})$ & $\theta_{e n}(\mathrm{rad})$ \\
\hline & & & \\
$\mathbf{1}$ & 0.00984 & 0.00077 & 3.142 \\
2 & $\mathbf{1 2 . 8 6 4 0 0}$ & $\mathbf{1 . 0 0 0 0 0}$ & $\mathbf{0}$ \\
$\mathbf{3}$ & 0.13700 & 0.01100 & 5.708 \\
4 & $\mathbf{0 . 6 3 6 0 0}$ & $\mathbf{0 . 0 4 9 0 0}$ & $\mathbf{3 . 1 1 8}$ \\
$\mathbf{5}$ & 0.03900 & 0.00306 & 2.914 \\
6 & $\mathbf{0 . 8 1 6 0 0}$ & $\mathbf{0 . 0 6 3 0 0}$ & $\mathbf{3 . 2 1 8}$ \\
$\mathbf{7}$ & 0.02000 & 0.00158 & 2.925 \\
8 & $\mathbf{0 . 1 8 9 0 0}$ & $\mathbf{0 . 0 1 5 0 0}$ & $\mathbf{6 . 2 6 2}$ \\
9 & 0.00701 & 0.00055 & 5.950 \\
& 0.13200 & 0.01000 & 2.775 \\
\hline
\end{tabular}

Table 3 Coefficients of phase back-EMF

\begin{tabular}{cccc}
\hline Gains & Values & Gains & Values \\
\hline$k_{e 1}$ & 1.088 & $k_{e 5}$ & $0.0630 / 5$ \\
$\theta_{e 1}$ & 0 & $\theta_{e 5}$ & 3.218 \\
$k_{e 3}$ & $0.049 / 3$ & $k_{e 7}$ & $0.0150 / 7$ \\
$\theta_{e 3}$ & 3.118 & $\theta_{e 7}$ & 6.262 \\
\hline
\end{tabular}

Table 4 Estimated torque of prototype PMSM

\begin{tabular}{ll}
\hline Current optimization & Torque $(p u)$ \\
\hline & \\
Fundamental current & 1.088 \\
Strategy-1 & 1.267 \\
Strategy-2 & $1.182+0.00612 \cos (12 \theta+3.183)$ \\
Strategy-3 & $1.347+0.00468 \cos (12 \theta+0.033)$ \\
\hline
\end{tabular}

\section{Control of Harmonic Current Injection}

In this section, the harmonic current control in DTPMSM will be introduced. Assuming the 3rd, 5th and 7th harmonic currents in the phase current are expressed as (15)

$$
\begin{aligned}
& i_{3 r d}+i_{5 t h}+i_{7 t h}= \\
& {\left[\begin{array}{c}
i_{a 3 r d}(\theta) \\
i_{a 3 r d}\left(\theta-\theta_{s}\right) \\
i_{a 3 r d}\left(\theta-4 \theta_{s}\right) \\
i_{a 3 r d}\left(\theta-5 \theta_{s}\right) \\
i_{a 3 r d}\left(\theta-8 \theta_{s}\right) \\
i_{a 3 r d}\left(\theta-9 \theta_{s}\right)
\end{array}\right]+\left[\begin{array}{c}
i_{a 5 t h}(\theta) \\
i_{a 5 t h}\left(\theta-\theta_{s}\right) \\
i_{a 5 t h}\left(\theta-4 \theta_{s}\right) \\
i_{a 5 t h}\left(\theta-5 \theta_{s}\right) \\
i_{a 5 t h}\left(\theta-8 \theta_{s}\right) \\
i_{a 5 t h}\left(\theta-9 \theta_{s}\right)
\end{array}\right]+\left[\begin{array}{c}
i_{a 7 t h}(\theta) \\
i_{a 7 t h}\left(\theta-\theta_{s}\right) \\
i_{a 7 t h}\left(\theta-4 \theta_{s}\right) \\
i_{a 7 t h}\left(\theta-5 \theta_{s}\right) \\
i_{a 7 t h}\left(\theta-8 \theta_{s}\right) \\
i_{a 7 t h}\left(\theta-9 \theta_{s}\right)
\end{array}\right]}
\end{aligned}
$$

where

$$
\begin{aligned}
& i_{a 3 r d}(\theta)=k_{i 3} \cos \left(\left(3(\theta+\pi / 2)+\theta_{i 3}\right)\right. \\
& i_{a 5 t h}(\theta)=k_{i 5} \cos \left(\left(5(\theta+\pi / 2)+\theta_{i 5}\right)\right. \\
& i_{a 7 t h}(\theta)=k_{i 7} \cos \left(\left(7(\theta+\pi / 2)+\theta_{i 7}\right)\right.
\end{aligned}
$$

According to the VSD theory for the dual three-phase system [26], the six-dimensional $a b c-x y z$ frame can be decomposed into three orthogonal sub-spaces, i.e. $\alpha \beta, z_{1} z_{2}$, $\mathrm{O}_{1} \mathrm{O}_{2}$ sub-planes.

$$
\begin{aligned}
{\left[\begin{array}{llllll}
F_{\alpha} & F_{\beta} & F_{z 1} & F_{z 2} & F_{o 1} & F_{o 2}
\end{array}\right]^{T} } \\
\quad=\left[T_{6}\right]\left[\begin{array}{llllll}
F_{a} & F_{x} & F_{b} & F_{y} & F_{c} & F_{z}
\end{array}\right]^{T}
\end{aligned}
$$

where $\left[T_{6}\right]$ is a transformation matrix $(6 \times 6)$ detailed in [27]. By (19), the fundamental, 3rd, 5th and 7th harmonics in the $a b c-x y z$ frame are projected to three different orthogonal subplanes. The fundamental in the $a b c-x y z$ frame is projected to the $\alpha \beta$ sub-plane; the 5th and 7th harmonics in the $a b c-x y z$ frame are projected to the $z_{1} z_{2}$ sub-plane; the 3rd harmonics in the $a b c-x y z$ frame are projected to $o_{1} o_{2}$ sub-plane. Consequently, the fundamental component, 5th and 7th harmonics, and 3rd harmonics can be regulated by controlling the fundamental component in the $\alpha \beta$ sub-plane, sixth harmonics in $z_{1} z_{2}$ sub-plane, and 3rd harmonics in $o_{1} O_{2}$ subplane respectively. As the control of fundamental currents in the $\alpha \beta$ sub-plane is the same as the conventional vector control for the single three-phase system, therefore, it will not be introduced in this paper; instead, the control of harmonic currents will be detailed as follows.

\subsection{Fifth and seventh harmonic current injection}

By applying the conventional Clark to currents in each single three-phase ABC and XYZ, and then followed by the conventional Park transformation, the 5th and 7 th harmonic currents are converted to sixth harmonic currents in the rotating synchronous frame ( $d q$-frame), which can be expressed as (20).

$$
\begin{aligned}
& i_{d 2_{-} 6 t h}=-i_{d 1_{-} 6 t h}=k_{i 5} \sin \left(6 \theta+\theta_{i 5}\right)-k_{i 7} \sin \left(6 \theta+\theta_{i 7}\right) \\
& i_{q 2_{-} 6 t h}=-i_{q 1_{1} 6 t h}=k_{i 5} \cos \left(6 \theta+\theta_{i 5}\right)+k_{i 7} \cos \left(6 \theta+\theta_{i 7}\right)
\end{aligned}
$$

where $i_{d 1_{-} 6 t h}$ and $i_{q 1 \_6 t h}$ are the sixth harmonic currents in $d q$-frame for phase $\mathrm{ABC}, i_{d 2_{-} 6 t h}$ and $i_{q 2 \_6 t h}$ are sixth harmonic currents in the $d q$-frame for phase XYZ. The (20) indicates that the 5th and 7th harmonic currents in phase ABC and phase $\mathrm{XYZ}$ are both mapped to sixth harmonics in the $d q$ frame. The $i_{d 1_{-} 6 t h}$ and $i_{d 2_{-} 6 t h}$ have the same magnitude, but they are opposite in phase, so is the relationship between $i_{q 1 \_6 t h}$ and $i_{q 2 \_6 t h}$.

By (19), the 5th and 7th harmonic currents $i_{5 t h}$ and $i_{7 t h}$ in (15) are projected to $z_{1} z_{2}$ sub-plane and then $\left[i_{z 1}\right.$ $\left.i_{z 2}\right]^{\mathrm{T}}$ can be obtained and expressed as 


$$
\left[\begin{array}{l}
i_{z 1} \\
i_{z 2}
\end{array}\right]=\left[\begin{array}{c}
-k_{i 5} \sin \left(5 \theta+\theta_{i 5}\right) \\
k_{i 5} \cos \left(5 \theta+\theta_{i 5}\right)
\end{array}\right]+\left[\begin{array}{l}
k_{i 7} \sin \left(7 \theta+\theta_{i 7}\right) \\
k_{i 7} \cos \left(7 \theta+\theta_{i 7}\right)
\end{array}\right]
$$

By applying (22) to $\left[i_{z l} i_{z_{2}}\right]^{\mathrm{T}}$ in $z_{1} z_{2}$ sub-plane [22], the 5th and 7th harmonic currents are mapped to sixth harmonic currents in a designated $d q z$-frame. Compared to the conventional Park transformation matrix, the $\left[T_{d q z}\right]$ in (22) represents matrix transformation to the negative-sequence synchronous reference frame with opposite $d$-axis.

$$
\left[\begin{array}{l}
F_{d z} \\
F_{q z}
\end{array}\right]=\left[T_{d q z}\right]\left[\begin{array}{l}
F_{z 1} \\
F_{z 2}
\end{array}\right],\left[T_{d q z}\right]=\left[\begin{array}{cc}
-\cos \theta & \sin \theta \\
\sin \theta & \cos \theta
\end{array}\right]
$$

The sixth harmonic currents in the $d q$-axis for each single three-phase $\mathrm{ABC}$ and $\mathrm{XYZ}$ and the sixth harmonics in $d q z$-frame in $z_{1} z_{2}$ sub-plane for the dual three-phase system have the relationship as (23).

$$
\left[\begin{array}{l}
F_{d z_{-} 6 t h} \\
F_{q z_{-} 6 t h}
\end{array}\right]=\left[\begin{array}{l}
F_{d 2_{-} 6 t h} \\
F_{q 2_{-} 6 t h}
\end{array}\right]=-\left[\begin{array}{l}
F_{d 1} 6 t h \\
F_{q 1} 6 t h
\end{array}\right]
$$

It can be seen from (23) that the sixth harmonic currents $i_{d 1 \_6 t h}$ and $i_{q 1 \_6 t h}$ in $d q$-frame for phase $\mathrm{ABC}$, $i_{d 2_{-} 6 t h}$ and $i_{q 2 \_6 t h}$ in $d q$-frame for phase XYZ can be regulated simultaneously by controlling the sixth harmonic currents $i_{d z_{-} 6 t h}$ and $i_{q z_{-} 6 t h}$ in $z_{I} z_{2}$ sub-plane in the $d q z_{\text {-frame. }}$ Consequently, the 5th and 7th harmonics in each phase can be controlled as well.

\subsection{Third harmonic current injection}

By (19), 3rd harmonic currents $i_{3 r d}$ in (15) projected to $\alpha \beta-z_{1} z_{2}-O_{1} O_{2}$ sub-planes can be expressed as

$$
\left[\begin{array}{c}
i_{o 1} \\
i_{o 2}
\end{array}\right]=\left[\begin{array}{l}
k_{i 3} \cos \left(\left(3(\theta+\pi / 2)+\theta_{i 3}\right)\right. \\
k_{i 3} \sin \left(\left(3(\theta+\pi / 2)+\theta_{i 3}\right)\right.
\end{array}\right]
$$

The (24) indicates the 3 rd harmonic currents in phase $\mathrm{ABC}$ and XYZ can be regulated by controlling $i_{o l}$ and $i_{o 2}$ in the $o_{1} o_{2}$ sub-plane respectively.

\subsection{VSD current control scheme}

The scheme of current control is shown in Fig. 4. Each phase current is sampled so that the zero-sequence currents in phase $\mathrm{ABC}$ and $\mathrm{XYZ}$, including the 3rd harmonic currents, can be obtained and regulated effectively. The fundamental, 5 th and 7 th harmonic currents, and 3rd harmonic currents are regulated in $\alpha \beta, z_{1} z_{2}$ and $o_{1} o_{2}$ sub-plane separately. The reference currents $i_{d z}^{*}, i_{q z}^{*}$ in $d q$-frame are from (23) and reference currents $i_{o 1}^{*}, i_{o 2}^{*}$ in $o_{1} O_{2}$ sub-plane are from (24), while the harmonic currents reference is from (1). Two PI controllers with resonance controllers (PI-R) [28-30] are adopted to regulate the sixth harmonic currents without tracing error in steady-state operation in $i_{d z}$ and $i_{q z}$ in $d q z$ frame, There are also two resonance controllers employed to regulate 3rd harmonic currents in $i_{o 1}$ and $i_{o 2}$ in $o_{1} O_{2}$ sub-plane.

Since the currents in $\alpha \beta-z_{1} z_{2}-O_{1} O_{2}$ sub-planes are controlled separately, 6-independent phase voltage commands including zero-sequence voltages are necessary. Therefore, 2-individual SPWM (sinusoidal pulse width modulation) strategy is adopted here considering the regulation of 3rd harmonic currents.

It is worth noting that an ideal integrator is often approximated by a low-pass transfer function in the resonance controller due to finite precision in digital systems in the practical application [28-30]. The harmonic voltages can be induced by the harmonic current injection, which is mixed up with the harmonic voltages from back-EMFs and inverter non-linearity; consequently, the peak voltage of references in the natural frame might be increased.

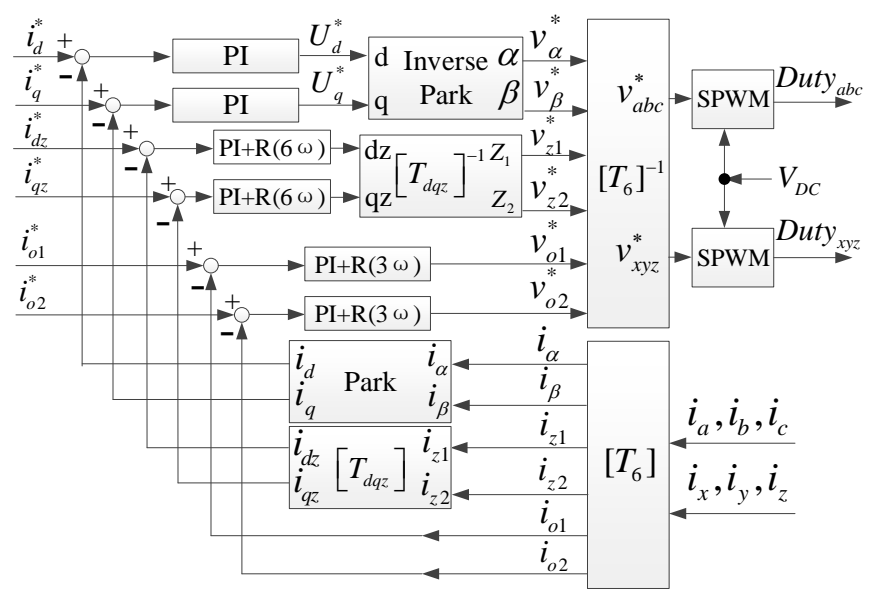

Fig. 4 3rd, 5th and 7th harmonic injection based on VSD current control

\section{Experiments}

To demonstrate the torque enhancement by utilization of harmonic currents, an existing prototype DT-PMSM is employed with different strategies of harmonic current injection, whose back-EMF and flux-linkage are shown in Fig. 3(a). The test rig is based on dSPACE DS1005, as shown in Fig. 5. The parameters of the prototype machine are given in Table 5. A PM DC generator connected with a power resistor is used as a variable load, which can be adjusted by changing the power resistor's resistance. The current loop is executed every PWM cycle $100 \mu$ s. The inverter power topology is the same as that in Fig. 1. Alternatively, the openend winding configuration can also be employed for the verification.

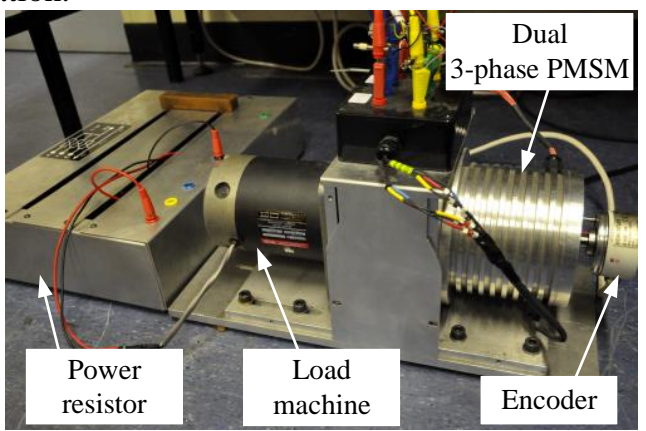

(a)

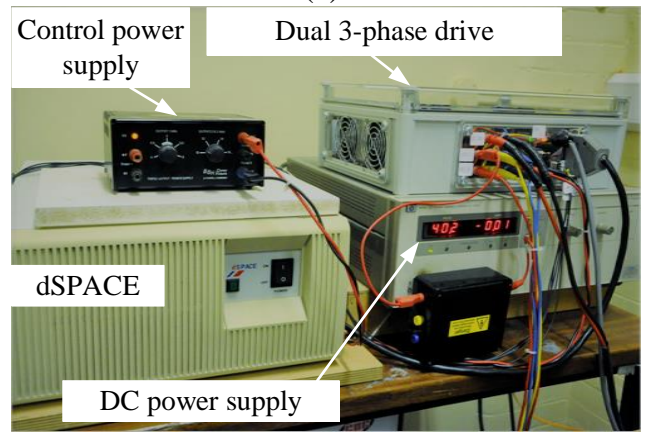

(b)

Fig. 5 Test platform for DT-PMSM

(a) Prototype DT-PMSM and load, (b) Dual three-phase inverter based on dSPACE 
Table 5 Design parameters of prototype DT-PMSM

\begin{tabular}{ll}
\hline Parameters & Value \\
\hline & \\
Rated power $(\mathrm{W})$ & 240 \\
DC bus voltage $(\mathrm{V})$ & 40 \\
Pole-pairs & 5 \\
Stator resistance $(\Omega)$ & 1.096 \\
$d$ - and $q$-axis self-inductance $(\mathrm{mH})$ & $2.141 / 2.141$ \\
Leakage inductance $(\mathrm{mH})$ & 0.875 \\
Flux-linkage $(\mathrm{Wb})$ & 0.075 \\
\hline
\end{tabular}

To investigate the torque enhancement of the prototype machine with different strategies of harmonic current injection, four experiments are conducted within 1A peak current value. The first is the current control without harmonic current injection; the second is the current control with Strategy-1; the third is the current control with Strategy2 ; the last is the current control with Strategy-3. In all experiments, the peak current value will be maintained to $1 \mathrm{~A}$ with the reference current having the same expression as (2) and the power resistor is the same all the time.

\subsection{Without the harmonic current injection}

The experimental results without $3 \mathrm{rd}$, 5th and 7 th harmonic current injection are illustrated in Fig. 6. The phase currents $i_{a}$ and $i_{x}$ are shown in the top half of Fig. 6(a), where it can be seen that the phase shift angle between $i_{a}$ and $i_{x}$ is $30^{\circ}$ and their peak values are $1 \mathrm{~A}$. The currents $i_{\alpha}$ and $i_{\beta}$ in the $\alpha \beta$ sub-plane are shown in the bottom half of Fig. 6(a), where the peak value of $i_{\alpha}$ and $i_{\beta}$ are 1A and they are very sinusoidal. The currents in the $z_{1} z_{2}$ sub-plane and the currents in the $o_{1} O_{2}$ sub-plane are shown in Fig. 6(b). As can be seen from Fig. 6(b), the currents of $i_{d z}, i_{q z}, i_{o 1}$, and $i_{o 2}$ are zeroes, which indicates that the 3rd, 5th and 7th harmonic currents are not injected to the phase currents. The harmonic analysis of phase currents is shown in Fig. 6(c), which shows that the fundamental is $1 \mathrm{~A}$ the $3 \mathrm{rd}$, 5th and 7 th harmonic currents are negligible. The speed is illustrated in Fig. 6(d) and the average speed during $0.4 \mathrm{~s}$ is about $158.04 \mathrm{rpm}$. The phase voltage $v_{a}$ and $v_{x}$ are illustrated in Fig. 6(e).

\subsection{Strategy-1: 3rd harmonic current injection}

The experimental results with Strategy-1 of 3rd harmonic current injection are shown in Fig. 7. The phase currents $i_{a}$ and $i_{x}$ are shown in the top half of Fig. 7 (a) and their peak values are $1 \mathrm{~A}$ as well. The fundamental currents mapped to the $\alpha \beta$ sub-plane are shown in the bottom half of Fig. 7 (a). The 5th and 7th harmonic currents mapped to the $z_{1} z_{2}$ sub-plane and the 3rd harmonic currents mapped to the $o_{1} O_{2}$ sub-plane are shown in Fig. 7 (b). As can be seen from the top half of Fig. 7 (b), the currents $i_{d z}$ and $i_{q z}$ are zeroes, but there are $3 \mathrm{rd}$ harmonic currents in $i_{o 1}$ and $i_{o 2}$ at the bottom half of Fig. 7 (b). The FFT analysis of phase currents is shown in Fig. 7 (c), where it shows that the fundamental current is 1.15 times of that in Fig. 6(c) and there are obvious 3rd harmonic currents inside, which is in accordance with the optimized gains for Strategy-1 in Table 1. The speed is illustrated in Fig. 7 (d) and the average speed during $0.4 \mathrm{~s}$ is around $186.78 \mathrm{rpm}$. The phase voltage $v_{a}$ and $v_{x}$ are illustrated in Fig. 7(e).

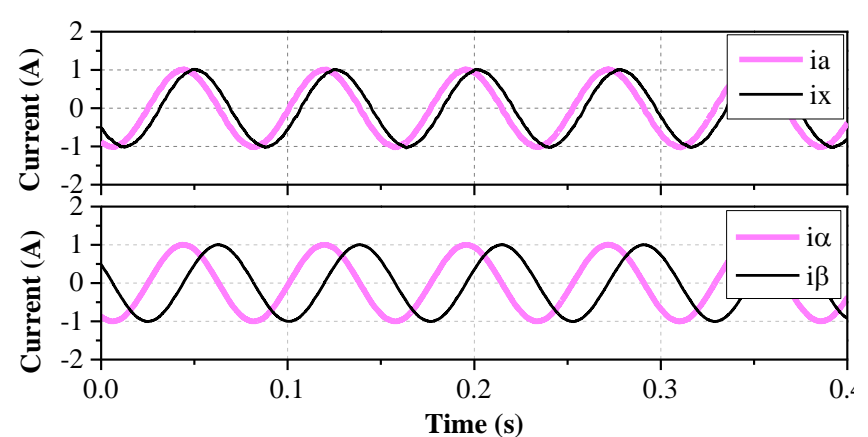

(a)

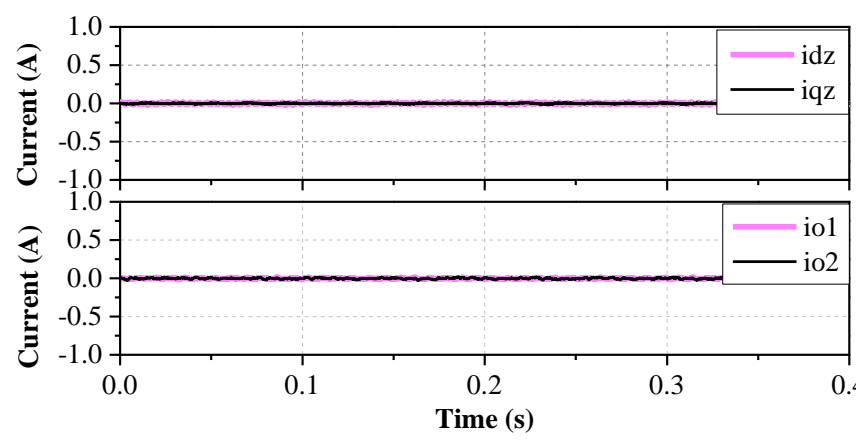

(b)

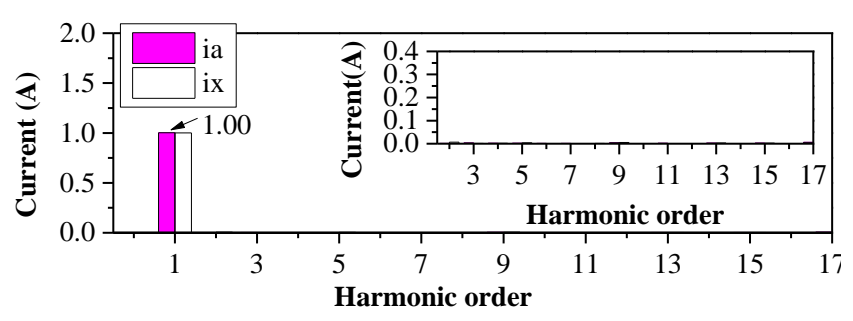

(c)

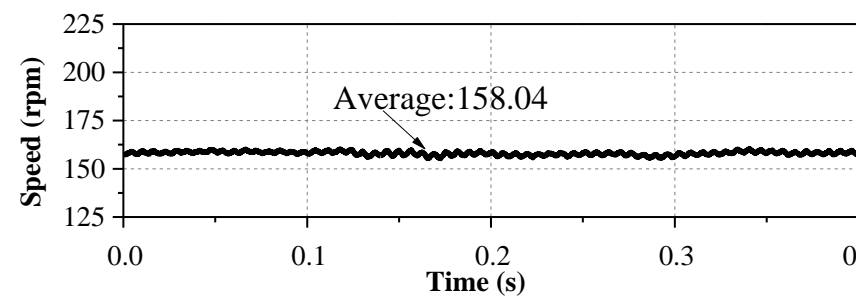

(d)

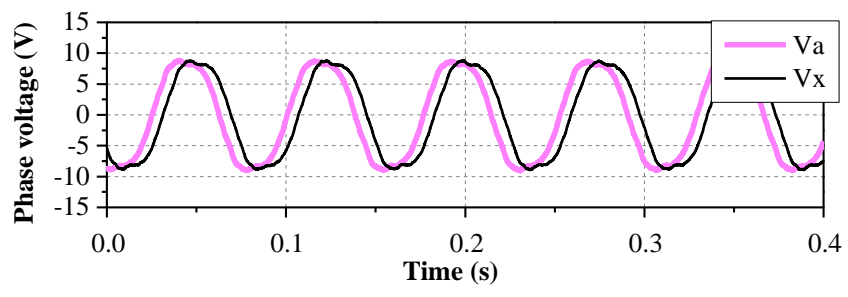

(e)

Fig. 6 Without harmonic current injection

(a) Phase currents $i_{a}$ and $i_{x}$ (top half), and currents in $\alpha \beta$ subplane (bottom half), (b) Currents in $d q z$-frame in $z_{1} z_{2}$ subplane (top half), and currents in $o_{1} O_{2}$ sub-plane (bottom half), (c) Harmonic analysis of phase currents, (d) Speed, (e) Phase voltages. 


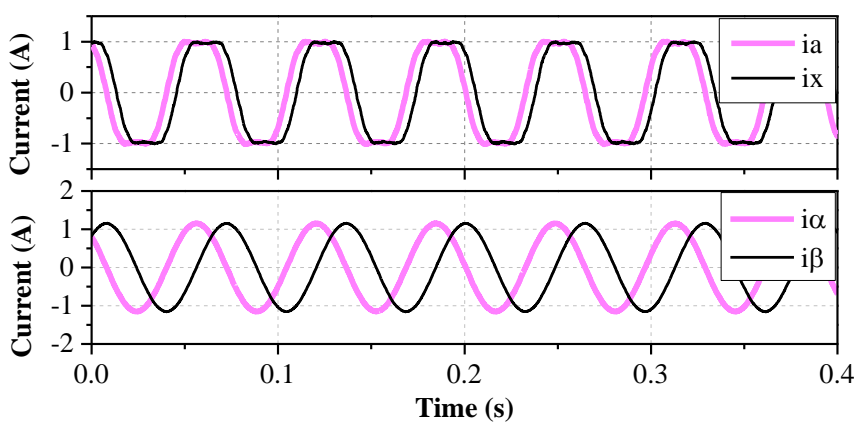

(a)

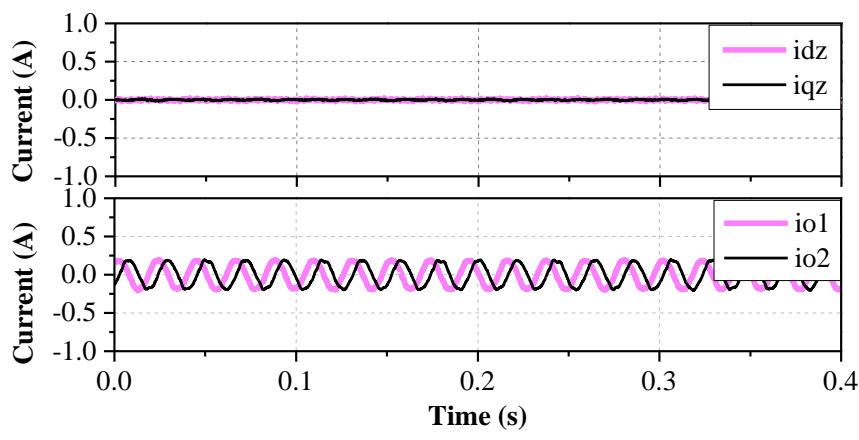

(b)

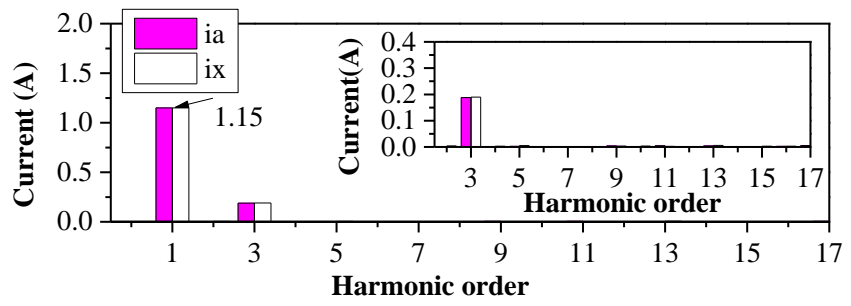

(c)

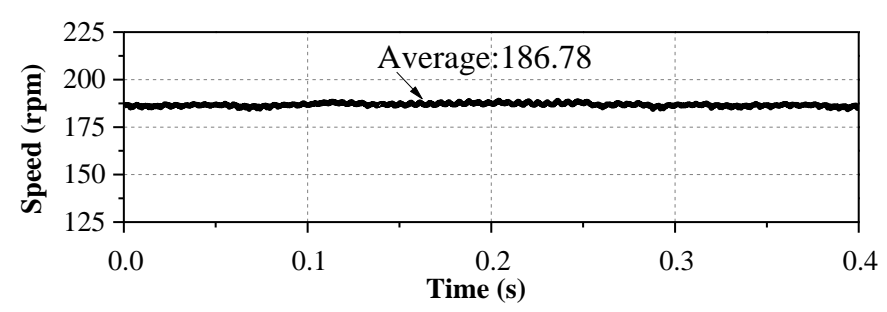

(d)

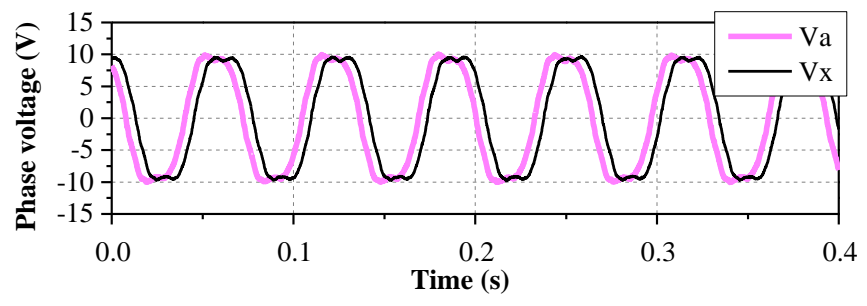

(e)

Fig. 7 With 3rd harmonic current injection (Strategy-1)

(a) Phase currents $i_{a}$ and $i_{x}$ (top half), and currents in $\alpha \beta$ subplane (bottom half), (b) Currents in $d q z$-frame in $z_{1} z_{2}$ sub-plane (top half), and currents in $\mathrm{O}_{1} \mathrm{O}_{2}$ sub-plane (bottom half), (c) Harmonic analysis of phase currents, (d) Speed, (e) Phase voltages.

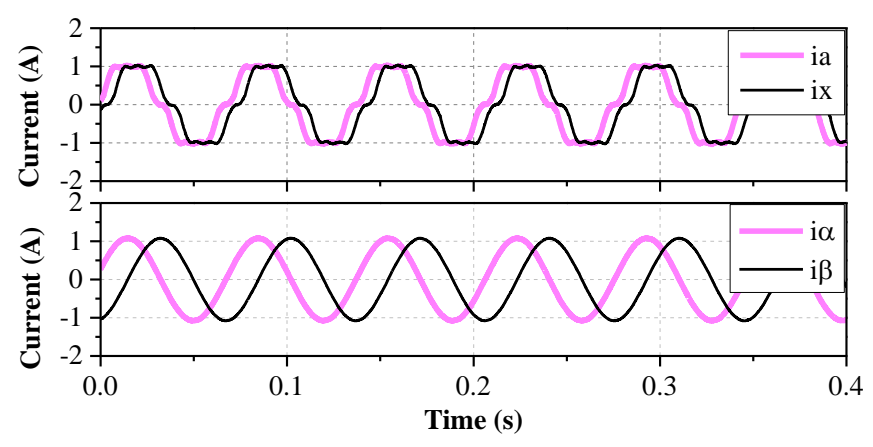

(a)

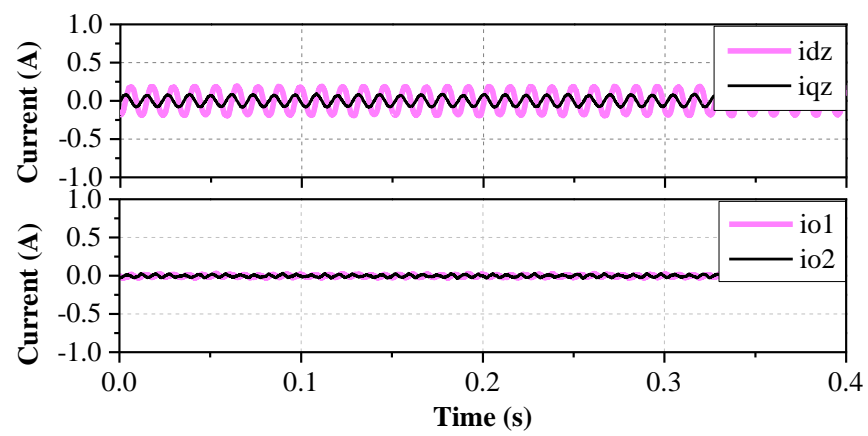

(b)

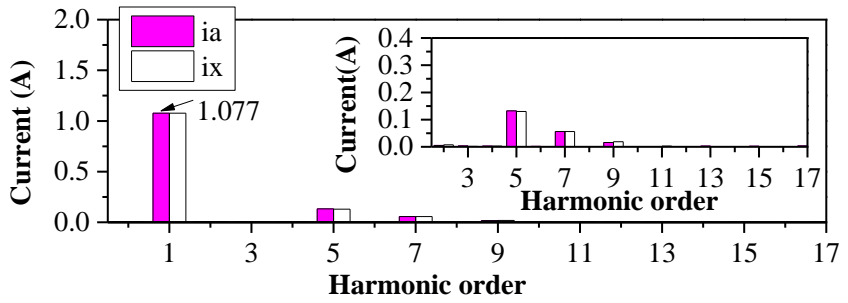

(c)

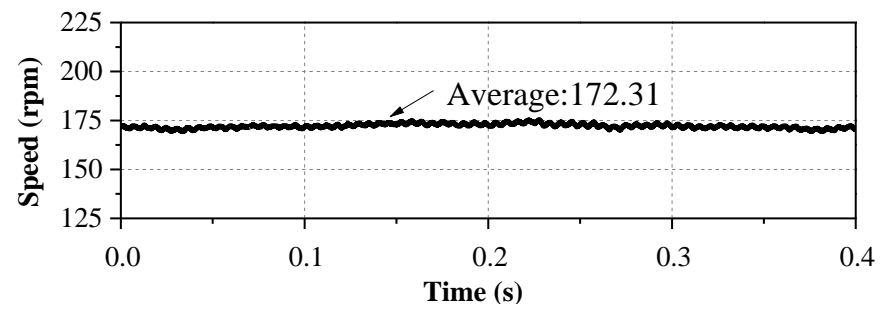

(d)

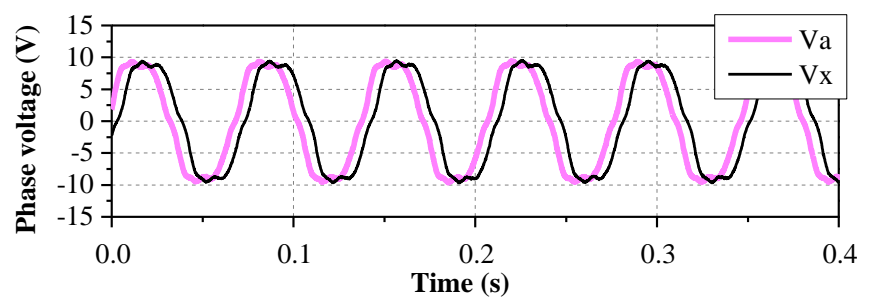

(e)

Fig. 8 With 5th, 7th harmonic current injection (Strategy-2)

(a) Phase currents $i_{a}$ and $i_{x}$ (top half), and currents in $\alpha \beta$ subplane (bottom half), (b) Currents in $d q z$-frame in $z_{1} z_{2}$ sub-plane (top half), and currents in $\mathrm{O}_{1} \mathrm{O}_{2}$ sub-plane (bottom half), (c) Harmonic analysis of phase currents, (d) Speed, (e) Phase voltages. 


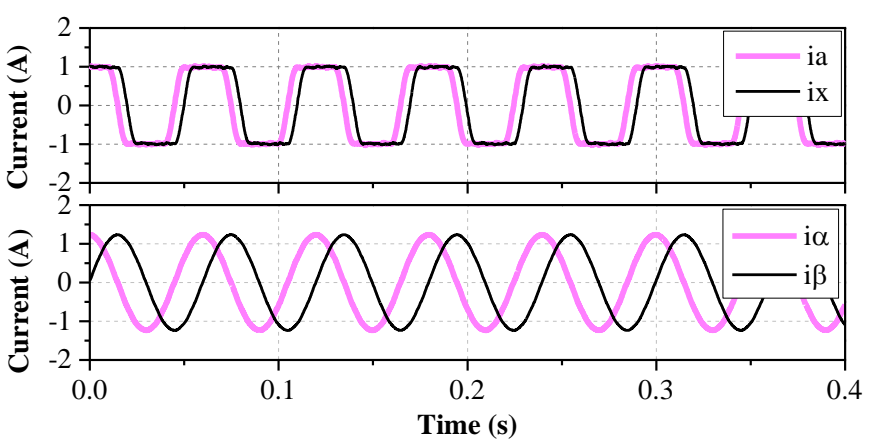

(a)

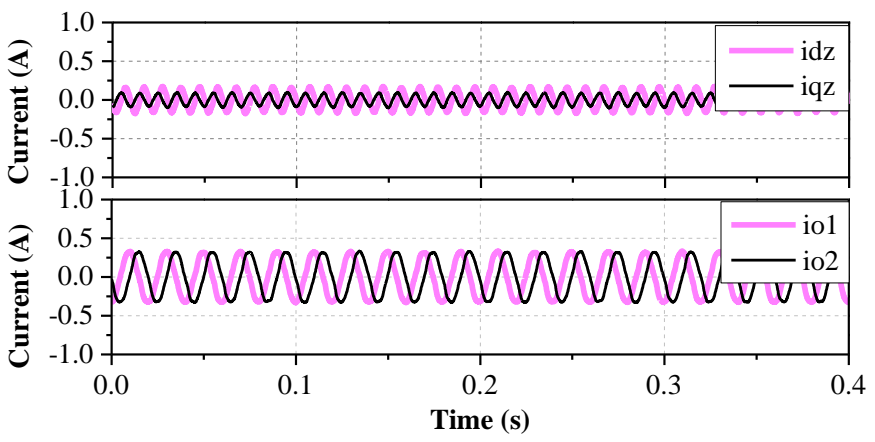

(b)

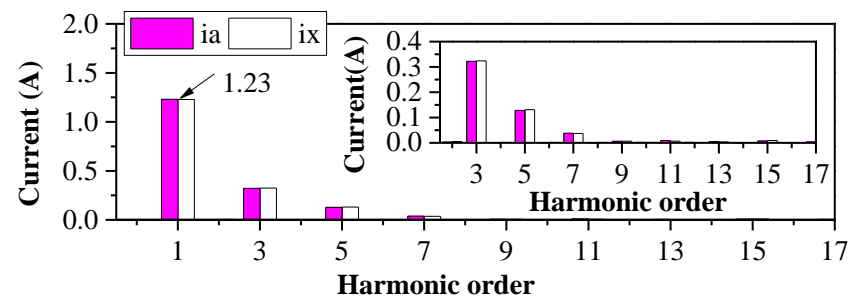

(c)

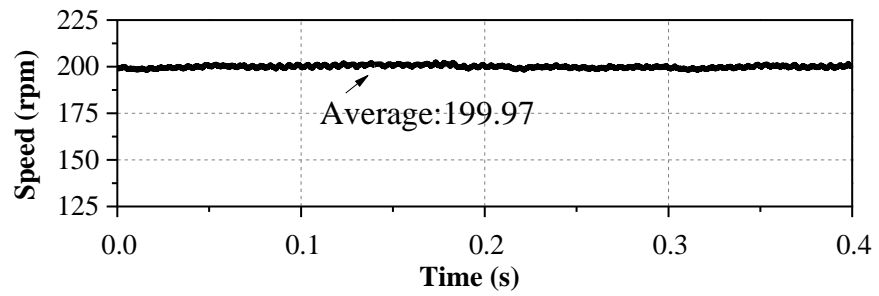

(d)

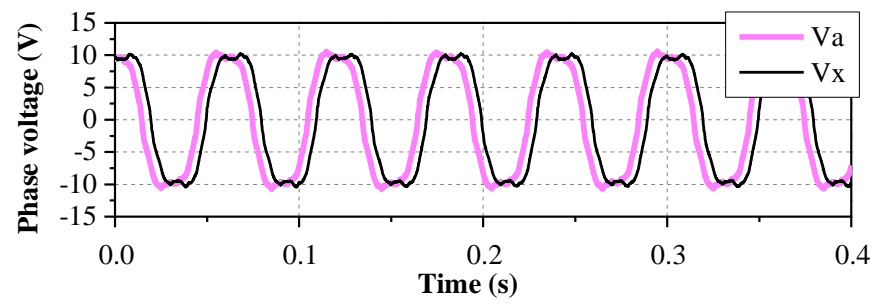

(e)

Fig. 9 With 3rd, 5th and 7th harmonic current injection (Strategy-3)

(a) Phase currents $i_{a}$ and $i_{x}$ (top half), and currents in $\alpha \beta$ subplane (bottom half), (b) Currents in $d q z$-frame in $z_{1} z_{2}$ sub-plane (top half), and currents in $O_{1} O_{2}$ sub-plane (bottom half), (c) Harmonic analysis of phase currents, (d) Speed, (e) Phase voltages.

\subsection{Strategy-2: 5th and 7th harmonic current injection}

The experimental results with Strategy-2 of 5th and 7th harmonic current injection are illustrated in Fig. 8. The phase currents $i_{a}$ and $i_{x}$ are shown in the top half of Fig. 8(a) and their peak values are $1 \mathrm{~A}$ as well. The fundamental currents mapped to the $\alpha \beta$ sub-plane are illustrated in the bottom half of Fig. 8 (a). The 5th and 7th harmonic currents mapped to the $z_{1} z_{2}$ subplane are shown in the top half of Fig. 8 (b). There are obvious 6th harmonic currents in $i_{d z}$, and $i_{q z}$. The 3rd harmonic currents mapped to the $o_{1} o_{2}$ sub-plane are shown in the bottom half of Fig. 8 (b). The $i_{o 1}$ and $i_{o 2}$ are zeros, which means there is no 3rd harmonic current injection. The FFT analysis of phase currents is shown in Fig. 8 (c), where it can be seen that the fundamental current is 1.077 times of that in Fig. 6(c), and there are obvious 5 th and 7 th harmonic currents, which are in accordance with the optimized gains for Strategy-2 in Table 1. The speed profile is illustrated in Fig. 8 (d) and the average speed during $0.4 \mathrm{~s}$ is around $172.31 \mathrm{rpm}$, which is lower than the speed in Fig. 7 (d). This is mainly because the fundamental current within the peak current in Strategy-2 is lower than Strategy-1. The phase voltage $v_{a}$ and $v_{x}$ are illustrated in Fig. 8(e).

\subsection{Strategy-3: 3rd, 5th and 7th harmonic current injection}

The experimental results with Strategy-3 of 3rd, 5th and 7th harmonic current injection are shown in Fig. 9. The phase currents are shown in the top half of Fig. 9 (a) and their peak values are $1 \mathrm{~A}$ as well. The fundamental currents mapped to the $\alpha \beta$ sub-plane are shown in the bottom half of Fig. 9 (a). The 5th and 7th harmonic currents mapped to the $z_{1} z_{2}$ sub-plane and the 3rd harmonic currents mapped to the $\mathrm{O}_{1} \mathrm{O}_{2}$ sub-plane are shown in the top and bottom half of Fig. 9 (b) respectively. As can be seen from Fig. 9, there are obvious 6th harmonic currents in $i_{d z}$ and $i_{q z}$ and $3 \mathrm{rd}$ harmonic currents in $i_{o 1}$ and $\mathrm{i}_{o 2}$, which indicates the $3 \mathrm{rd}$, 5th and 7 th harmonic currents are injected to the phase currents. The FFT analysis of phase currents is illustrated in Fig. 9 (c), where it shows that the fundamental current is 1.23 times of that in Fig. 6(c), and there are 3rd, 5th and 7th harmonic currents, which are in accordance with the optimized coefficients for Strategy-3 in Table 1. The measured speed is illustrated in Fig. 9 (d) and the average speed during $0.4 \mathrm{~s}$ is about $199.97 \mathrm{rpm}$. The phase voltage $v_{a}$ and $v_{x}$ are illustrated in Fig. 9(e).

\subsection{Summary}

The experimental results show that the fundamental currents in Fig. 7(c), Fig. 8(c) and Fig. 9(c) with different strategies of harmonic current injection are higher than that in Fig. 6(c) without harmonic current injection, which indicates more torque can be generated within the same current limit. Since a PM DC generator is employed as the load, if the friction is neglected, the power produced by the prototype DT-PMSM is equal to the power consumed by the PM DC generator, i.e.

$$
T_{e} \frac{\omega}{p}=\frac{E_{L}^{2}}{R_{L}} \propto \frac{\omega^{2}}{R_{L}}
$$


where $T_{e}, p$ and $\omega$ are the torque, the number of pole-pairs and electrical speed of prototype dual three-phase machine, $R_{L}$ is the sum of resistances of the adjustable power resistor and stator resistor of the PM DC generator, $E_{L}$ is the back-EMF of the PM DC generator. Since $E_{L}$ is proportional to $\omega$, it can be derived from (25) that $T_{e}$ is proportional to the speed

$$
T_{e} \propto \omega
$$

Therefore, the average torque with different strategies is reflected by their speed. Assuming the speed without harmonic current injection is $1 p u$, the measured speeds with different strategies can be listed in Table 6. It shows that the measured speeds are in accordance with the predicted speeds very well, which means the torque is boosted by different strategies of harmonic current injection.

Assuming the RMS current in the experiment without harmonic current injection is $1 p u$, then the RMS currents with Strategy-1, Strategy-2, and Strategy-3 are 1.171pu, 1.087pu, $1.281 p u$ respectively, and the torque per RMS current is $1.010 p u, 1.003 p u, 0.988 p u$, which means the average torque can be boosted significantly within the same peak current without deterioration of copper loss. Compared with the torque without harmonic current injection, the Strategy-1 can approximately improve the torque capability by $18.2 \%$ and the Strategy- 2 can extend the torque by $9.0 \%$, while the Strategy- 3 can boost the torque by $26.5 \%$, which is much better than these other two strategies.

Table 6 Torque capability extension by harmonic current injection to prototype machine

\begin{tabular}{|c|c|c|c|c|}
\hline Index & $\begin{array}{c}\text { Without } \\
\text { Harmonics }\end{array}$ & \begin{tabular}{|c|} 
Strategy \\
1 \\
\end{tabular} & \begin{tabular}{|c|} 
Strategy \\
2 \\
\end{tabular} & \begin{tabular}{|c} 
Strategy \\
3 \\
\end{tabular} \\
\hline Predicted torque $(p u)$ & 1.088 & 1.267 & 1.182 & 1.347 \\
\hline Predicted Speed $(p u)$ & 1 & 1.165 & 1.086 & 1.238 \\
\hline Test speed(rpm) & 158.04 & 186.77 & 172.31 & 199.97 \\
\hline Test speed $(p u)$ & 1 & 1.182 & 1.090 & 1.265 \\
\hline Peak current $(p u)$ & 1 & 1 & 1 & 1 \\
\hline Torque/Peak $(p u)$ & 1 & 1.182 & 1.090 & 1.265 \\
\hline RMS current $(p u)$ & 1 & 1.171 & 1.087 & 1.281 \\
\hline Torque/RMS $(p u)$ & 1 & 1.010 & 1.003 & 0.988 \\
\hline
\end{tabular}

\section{Conclusion}

This paper systematically investigates the torque boost of DT-PMSM drive system by different strategies of harmonics utilization. Three different strategies of harmonics utilization, i.e. Strategy-1 of 3rd harmonic injection, Strategy-2 of 5th and 7th harmonic injection, and the proposed Strategy-3 of 3rd, 5th and 7 th harmonic injection are evaluated. The results show that the torque of the DT-PMSM drive system can be further boosted by Strategy-3 within the current limit. The torque per RMS current can be increased significantly by the exploitation of harmonic flux-linkages and can be further increased by harmonic current injection. Compared with the current control without harmonic current injection to the prototype DT-PMSM, the average torque per peak current can be increased up to $1.182,1.090$ and 1.265 times by Strategy-1, Strategy-2, and Strategy-3 respectively. If the prototype is replaced by the ideal machine with optimized flux, i.e. Strategy-3 for flux, compared with the machine without harmonic flux and current utilization, the average torque per peak current can be increased up to 1.611, 1.224, and 1.928 times by Strategy-1, Strategy-2, and Strategy-3 of harmonic current injection respectively. Compared with Strategy-1 and Strategy-2 within the same peak current, the torque of Strategy-3 increases by $7.00 \%$ and $16.06 \%$ for the prototype DT-PMSM at the cost of $9.39 \%$ and $17.85 \%$ higher RMS current than Strategy-1 and Strategy-2 respectively. Nevertherless, the torque of Strategy-3 can be $19.68 \%$ and $54.98 \%$ higher than Strategy-1 and Strategy-2 respectively for the ideal machine.

\section{References}

[1] R. Hyung-Min, K. Jang-Hwan, and S. Seung-Ki, "Analysis of multiphase space vector pulse-width modulation based on multiple d-q spaces concept," IEEE Trans. Power Electron., vol. 20, no. 6, pp. 1364-1371, 2005.

[2] J. W. Kelly, E. G. Strangas, and J. M. Miller, "Multiphase space vector pulse width modulation," IEEE Trans. Energy Convers., vol. 18, no. 2, pp. 259-264, 2003.

[3] K. Gopakumar, S. Sathiakumar, S. K. Biswas, and J. Vithayathil, "Modified current source inverter fed induction motor drive with reduced torque pulsations," IEE Proc. B Elect. Power Appl., vol. 131, no. 4, pp. 159-164, 1984.

[4] Z. Q. Zhu, K. Wang, and G. Ombach, "Optimal magnet shaping with third order harmonic for maximum torque in brushless AC machines," in Proc. 6th IET Int. Conf. Power Electron., Mach. Drives, 2012, pp. 1-6.

[5] K. Wang, Z. Q. Zhu, and G. Ombach, "Torque enhancement of surfacemounted permanent magnet machine using 3rd order harmonic," IEEE Trans. Magn., vol. PP, no. 99, pp. 1-1, 2013.

[6] K. Wang, Z. Q. Zhu, G. Ombach, and W. Chlebosz, "Average torque improvement of interior permanent-magnet machine using 3rd harmonic in rotor shape," IEEE Trans. Ind. Electron., vol. PP, no. 99, pp. 1-1, 2013.

[7] G. Li, K. Zhang, Z. Q. Zhu, and G. Jewell, "Comparative studies of torque performance improvement for different doubly salient synchronous reluctance machines by current harmonic injection," IEEE Trans. Energy Convers., pp. 1-1, 2018.

[8] J. Feng, L. Huang, Z. Q. Zhu, S. Guo, and J. Shi, "Torque density enhancement of 6/4 variable flux reluctance machine with 2nd harmonic current injection," IEEE Trans. Energy Convers., pp. 1-1, 2018.

[9] E. Levi, "Multiphase electric machines for variable-speed applications," IEEE Trans. Ind. Electron., vol. 55, no. 5, pp. 1893-1909, 2008.

[10] E. A. Klingshirn, "High phase order induction motors - Part I-Description and theoretical considerations," IEEE Transactions on Power Apparatus and Systems, vol. PAS-102, no. 1, pp. 47-53, 1983.

[11] E. A. Klingshirn, "High phase order induction motors - Part IIExperimental results," IEEE Transactions on Power Apparatus and Systems, vol. PAS-102, no. 1, pp. 54-59, 1983.

[12] M. J. Duran, F. Salas, and M. R. Arahal, "Bifurcation analysis of fivephase induction motor drives with third harmonic injection," IEEE Trans. Ind. Electron., vol. 55, no. 5, pp. 2006-2014, 2008.

[13] H. Xu, H. A. Toliyat, and L. J. Petersen, "Five-phase induction motor drives with DSP-based control system," IEEE Trans. Power Electron., vol. 17, no. 4, pp. 524-533, 2002.

[14] L. Parsa and H. A. Toliyat, "Five-phase permanent-magnet motor drives," IEEE Trans. Ind. Appl., vol. 41, no. 1, pp. 30-37, 2005.

[15] J. Wang, R. H. Qu, and L. B. Zhou, "Dual-rotor multiphase permanent magnet machine with harmonic injection to enhance torque density," IEEE Trans. Appl. Supercond., vol. 22, no. 3, pp. 5202204-5202204, 2012.

[16] A. S. Abdel-Khalik, M. I. Masoud, and B. W. Williams, "Improved flux pattern with third harmonic injection for multiphase induction machines," IEEE Trans. Power Electron., vol. 27, no. 3, pp. 1563-1578, 2012.

[17] C. Coates, D. Platt, and V. J. Gosbell, "Performance evaluation of a ninephase synchronous reluctance drive," in Proc. 36th IAS Annu. Meeting Ind. Appl. Conf., 2001, pp. 2041-2047 vol.3.

[18] A. Abdelkhalik, M. Masoud, and W. Barry, "Eleven-phase induction machine: steady-state analysis and performance evaluation with harmonic injection," IET Electr. Power Appl., vol. 4, no. 8, pp. 670-685, 2010. 
[19] R. O. C. Lyra and T. A. Lipo, "Torque density improvement in a sixphase induction motor with third harmonic current injection," IEEE Trans. Ind. Appl., vol. 38, no. 5, pp. 1351-1360, 2002.

[20] K. Wang, Z. Q. Zhu, Y. Ren, and G. Ombach, "Torque improvement of dual three-phase permanent-magnet machine with third-harmonic current injection," IEEE Trans. Ind. Electron., vol. 62, no. 11, pp. 6833$6844,2015$.

[21] K. Wang, J. Y. Zhang, Z. Y. Gu, H. Y. Sun, and Z. Q. Zhu, "Torque improvement of dual three-phase permanent magnet machine using zero sequence components," IEEE Trans. Magn., vol. 53, no. 11, pp. 1-4, 2017.

[22] Y. Hu, Z. Q. Zhu, and M. Odavic, "Torque capability enhancement of dual three-phase PMSM drive with fifth and seventh current harmonics injection," IEEE Trans. Ind. Appl., vol. 53, no. 5, pp. 4526-4535, 2017.

[23] G. Feng, C. Lai, M. Kelly, and N. C. Kar, "Dual three-phase PMSM torque modeling and maximum torque per peak current control through optimized harmonic current injection," IEEE Trans. Ind. Electron., vol. 66, no. 5, pp. 3356-3368, 2019.

[24] K. Gopakumar, V. T. Ranganthan, and S. R. Bhat, "Split-phase induction motor operation from PWM voltage source inverter," IEEE Trans. Ind. Appl., vol. 29, no. 5, pp. 927-932, 1993.
[25] A. S. Abdel-Khalik, S. Mostafa Gadoue, M. I. Masoud, and B. W. Wiliams, "Optimum flux distribution with harmonic injection for a multiphase induction machine using genetic algorithms," IEEE Trans. Energy Convers., vol. 26, no. 2, pp. 501-512, 2011.

[26] Y. F. Zhao and T. A. Lipo, "Space vector PWM control of dual threephase induction machine using vector space decomposition," IEEE Trans. Ind. Appl., vol. 31, no. 5, pp. 1100-1109, 1995.

[27] Y. Hu, Z. Q. Zhu, and K. Liu, "Current control for dual three-phase permanent magnet synchronous motors accounting for current unbalance and harmonics," IEEE Journal of Emerging and Selected Topics in Power Electronics, vol. 2, no. 2, pp. 272-284, 2014.

[28] D. N. Zmood, D. G. Holmes, and G. H. Bode, "Frequency-domain analysis of three-phase linear current regulators," IEEE Trans. Ind. Appl., vol. 37, no. 2, pp. 601-610, 2001.

[29] D. N. Zmood and D. G. Holmes, "Stationary frame current regulation of PWM inverters with zero steady-state error," IEEE Trans. Power Electron., vol. 18, no. 3, pp. 814-822, 2003.

[30] L. R. Limongi, R. Bojoi, G. Griva, and A. Tenconi, "Digital currentcontrol schemes," IEEE Ind. Electron. Mag., vol. 3, no. 1, pp. 20-31, 2009.

\section{Appendix}

Table 7 Torque capability extension by different strategies of harmonics utilization

\begin{tabular}{|c|c|c|c|c|}
\hline Flux $\begin{array}{c}\text { Current } \\
\text { optimization }\end{array}$ & Fundamental current & $\begin{array}{l}\text { Strategy-1: } \\
\text { 3rd harmonic } \\
\text { injection }\end{array}$ & $\begin{array}{c}\text { Strategy-2: } \\
\text { 5th and 7th harmonic injection }\end{array}$ & $\begin{array}{l}\text { Strategy-3: } \\
\text { 3rd, 5th, and 7th harmonic } \\
\text { injection }\end{array}$ \\
\hline $\begin{array}{l}\text { Fundamental } \\
\text { with } 6 \text { VSI legs }\end{array}$ & $\begin{array}{l}\text { Fundamental Flux: } 1 \\
\text { Fundamental Current: } 1 \\
\text { Torque: } 1 \\
\text { Torque/peak current: } 1 \\
\text { Torque/RMS current: } 1\end{array}$ & $\begin{array}{l}\text { Fundamental Flux: } 1 \\
\text { Fundamental Current: } 1.15 \\
\text { Torque: } 1.15 \\
\text { Torque/peak current: } 1.15 \\
\text { Torque/RMS current: } 0.986\end{array}$ & $\begin{array}{l}\text { Fundamental Flux: } 1 \\
\text { Fundamental Current: } 1.077 \\
\text { Torque: } 1.077 \\
\text { Torque/peak current: } 1.077 \\
\text { Torque/RMS current: } 0.990\end{array}$ & $\begin{array}{l}\text { Fundamental Flux: } 1 \\
\text { Fundamental Current: } 1.231 \\
\text { Torque: } 1.231 \\
\text { Torque/peak current: } 1.231 \\
\text { Torque/RMS current: } 0.961\end{array}$ \\
\hline $\begin{array}{c}\text { Strategy-2 } \\
\text { with } 6 \text { VSI legs: } \\
\text { 5th and 7th harmonic } \\
\text { injection }\end{array}$ & $\begin{array}{l}\text { Fundamental Flux: } 1.077 \\
\text { Fundamental Current: } 1 \\
\text { Torque: } 1.077 \\
\text { Torque/peak current: } 1.077 \\
\text { Torque/RMS current: } 1.077\end{array}$ & $\begin{array}{l}\text { Fundamental Flux: } 1.077 \\
\text { Fundamental Current: } 1.15 \\
\text { Torque: } 1.244 \\
\text { Torque/peak current: } 1.244 \\
\text { Torque/RMS current: } 1.062\end{array}$ & $\begin{array}{l}\text { Fundamental Flux: } 1.077 \\
\text { Fundamental Current: } 1.077 \\
\text { Torque: } 1.275-0.093 \cos (12 \theta) \\
\text { Torque/peak current: } 1.275 \\
\text { Torque/RMS current: } 1.173\end{array}$ & $\begin{array}{l}\text { Fundamental Flux: } 1.077 \\
\text { Fundamental Current: } 1.231 \\
\text { Torque: } 1.224+0.077 \cos (12 \theta) \\
\text { Torque/peak current: } 1.224 \\
\text { Torque/RMS current: } 0.956\end{array}$ \\
\hline
\end{tabular}

Note: The current peaks are the same in all the strategies. 